\title{
Sverdrup and Nonlinear Dynamics of the Pacific Equatorial Currents*
}

\author{
William S. Kessler, Gregory C. Johnson, and Dennis W. Moore \\ NOAA/Pacific Marine Environmental Laboratory, Seattle, Washington
}

(Manuscript received 10 December 2001, in final form 23 October 2002)

\begin{abstract}
The Sverdrup circulation in the tropical Pacific is constructed from satellite scatterometer winds, compared with measured ocean currents, and diagnosed in an ocean GCM. Previous depictions of the Sverdrup circulation near the equator have shown only weak vertically integrated flows; here it is shown that the actual transports are not weak. This discrepancy could be due either to inaccuracies in the wind forcing or to Sverdrup dynamics being too simple in this region. Scatterometer winds show a strip of positive curl along the SST front north of the equator in the eastern Pacific that is due to wind speed changes induced by the front. Including that additional element of curl forcing greatly improves the realism of the Sverdrup representation, but the magnitudes of the equatorial transport are still too small by a factor of about 2. Although the nonlinear (advective and friction) terms are small in the model momentum balance, they are $O(1)$ in the vorticity balance, especially because their meridional derivatives are large near the equator. Examining the effect of the nonlinear terms through the vorticity balance shows that advection acts to intensify the mean currents of the tropical Pacific, including both the Equatorial Undercurrent and the westward off-equatorial South Equatorial Current. However, the principal nonlinearity is due to the acceleration and deceleration of the Equatorial Undercurrent, not to meridional convergence as has been previously argued.
\end{abstract}

\section{Introduction}

Since Sverdrup's (1947) demonstration that the flow of the North Equatorial Countercurrent against the wind was due to the vorticity (stretching) imposed by the wind stress curl, Sverdrup theory has been prominent in diagnoses of the tropical circulation in the Pacific. A variety of observational (Meyers 1980; McPhaden and Taft 1988; Godfrey 1989; Landsteiner et al. 1990; Yu and McPhaden 1999) and model (McCreary 1981; Qiu and Lukas 1996; Wajsowicz 1999; McCreary et al. 2002; among many others) studies have demonstrated that fundamental aspects of the tropical Pacific current systems can be understood in terms of these linear ideas. There has, however, been little opportunity to study the circulation just off the equator, where geostrophy is questionable and difficult to apply, so the ability to examine these questions has been very limited. New direct measurements of these currents (Johnson et al. 2002) now make such examination more feasible.

Although the Sverdrup circulation has been successful in explaining many aspects of the tropical Pacific,

\footnotetext{
* Pacific Marine Environmental Laboratory Contribution Number 2443.

Corresponding author address: William S. Kessler, NOAA/Pacific Marine Environmental Laboratory, 7600 Sand Point Way NE, Seattle, WA 98115.

E-mail: kessler@pmel.noaa.gov
}

a puzzling aspect has been that the Sverdrup zonal currents along and near the equator are consistently found to be very weak when derived from several often-used wind products (Kessler and Taft 1987; Landsteiner et al. 1990). This result appears to contradict observations of the strong eastward Equatorial Undercurrent (EUC) and the westward South Equatorial Current (SEC) branches flanking it. There are three possible explanations for this discrepancy: 1) despite the strong upperocean currents the vertically integrated transport is in fact near zero; 2) there are systematic errors in the wind products; and 3) Sverdrup dynamics are too simple to describe the equatorial currents. Knowledge of the deep flows in this region is sparse. It has not been (and is still not) possible to show unambiguously that the deep flow does not compensate for the upper currents, but this appears unlikely (Firing 1987).

In this paper we examine the other two possible explanations, based on satellite scatterometer winds and an ocean GCM. Scatterometry has shown new elements of the wind-stress-curl forcing in the tropical Pacific that ship and reanalysis wind products omit or smooth out (Chelton et al. 2001). Although these mean curl signatures are not large in themselves, the Sverdrup zonal transport depends on the meridional gradient of the curl, and Sverdrup transports calculated from scatterometer winds agree much better with the new direct current observations than do those from previous wind products. A model, driven by scatterometer winds, is 


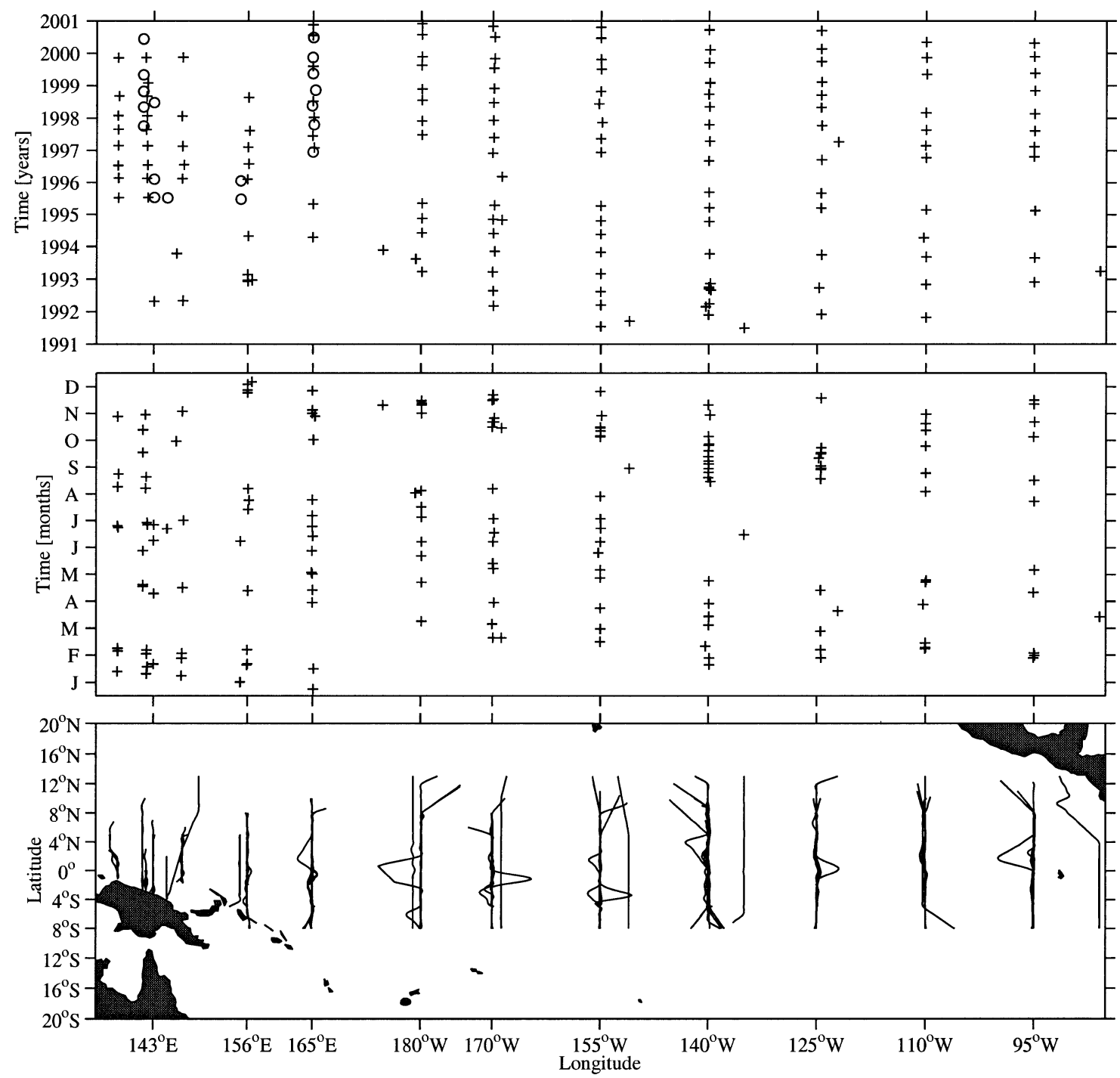

FIG. 1. (top) Equator-crossing dates of the 172 meridional CTD/ADCP sections used in this study. Sections occupied between 1991 and 2001 are shown by (+); sections occupied between 1985 and 1990 are shown by (o), with 10 years added to these dates for compactness. (middle) Equator-crossing dates by time of year. (bottom) Map of the ship tracks (note that most of the tracks overlie each other along the TAO buoy lines).

necessary to diagnose the importance of advection and friction since the direct current observations are not adequate to the task. While the model nonlinear terms are small, taking their curl (in analogy to the Sverdrup balance) shows how these small departures from the linear balance significantly alter the modeled mean currents and further improve their agreement with directly measured currents.

\section{Data and model}

\section{a. Acoustic Doppler current profiler (ADCP) data}

The 172 nominally meridional CTD/ADCP sections used in this study were taken from June 1985 through December 2000 principally on cruises to service the
TAO (Tropical Atmosphere-Ocean) and TRITON (Triangle Trans-Ocean Buoy Network) mooring arrays (Hayes et al. 1991; McPhaden et al. 1998). Other cruises were made during programs of American, French, Japanese, and Chinese national and academic institutions, especially before 1990. The ship tracks generally followed the ten meridional lines of the buoy network, which are separated by $10^{\circ}$ to $15^{\circ}$ longitude (Fig. 1); the cruises were made roughly twice per year on each line and were fairly evenly distributed during the 1990s. The seasonal distribution is less than ideal, with a concentration of cruises in particular seasons, especially boreal fall (Fig. 1, middle); the harmonic fitting method used to produce the gridded means helps to avoid the bias that would result from a simple average. However, 
it is still possible that the lack of sampling in boreal summer does degrade the fit.

A complete set of meridional and zonal sections of temperature, salinity, and zonal velocity from this dataset is shown in Johnson et al. (2002), along with some derived quantities. The use of these data for the present study was inspired by questions raised in that work and is based on the identical data and processing. Briefly, velocities for each individual section were objectively mapped onto isopycnals, with meridional and vertical correlation length scales of $1^{\circ}$ and $25 \mathrm{~m}$, respectively. The ADCP typically samples between 20 and $400 \mathrm{~m}$, and the upper shear was used to extrapolate values to the surface. The effect of this extrapolation was checked by recomputing the vertically integrated transports with the $25-\mathrm{m}$ velocity extended to the surface; the largest differences from the extrapolated transport shown in Fig. 3 (top) are in the far east where the Equatorial Undercurrent is close to the surface (Fig. 2, top left). The maximum difference was $6.6 \mathrm{~m}^{2} \mathrm{~s}^{-1}$, which is less than the first contour interval used in Fig. 3, and we conclude that the shear extrapolation is a reasonable choice. Once the individual sections were gridded, they were analyzed around each of the 10 nominal longitudes using an isopycnal averaging procedure that preserves the sharp pycnocline and velocity extrema (Johnson et al. 2002). Data at each latitude and isopycnal were fitted with a polynomial function of longitude, an annual harmonic, and the Southern Oscillation index. Each fit included data within $22^{\circ}$ of the target longitude to maximize the number of observations. In the present work only the fitted mean is studied; see Johnson et al. (2002) for a description of the seasonal cycle and ENSO-related variations.

\section{b. Wind data}

European Remote Sensing (ERS) satellite scatterometer winds are used here both to calculate the Sverdrup transports and to force the OGCM described in section 2c below. The ERS-1 satellite was launched in July 1991, and its nearly identical follow-on mission ERS-2 was launched in April 1995 and remains in operation. The ERS scatterometer samples a swath $500 \mathrm{~km}$ wide with an effective along-track resolution of $50 \mathrm{~km}$ (Stoffelen and Anderson 1997) and has been in several orbit configurations during these missions (primarily a 35-day repeat cycle). The winds used here were processed into monthly $1^{\circ}$ latitude by $1^{\circ}$ longitude gridded fields of stress components by the French satellite data processing facility Centre ERS d'Archivage et de Traitement (CERSAT), and were obtained by ftp from the CERSAT Web site (http://www.ifremer.fr/cersat/) for the period August 1991-December 2000. A monthly average annual cycle of stress components was constructed from the $9.5 \mathrm{yr}$ of data to produce forcing fields for the OGCM, and the mean of that cycle was used for the curl and Sverdrup transports.

\section{c. Ocean GCM}

The tropical upper-ocean GCM used in this study consists of two physical components: the sigma layer, tropical primitive equation general circulation model of Gent and Cane (1989), with the "hybrid" mixed layer formulation developed by Chen et al. (1994a,b) as its surface boundary layer. The entire model domain is the upper active layer (roughly $400 \mathrm{~m}$ thick) of a reducedgravity ocean, assumed to overlie an infinitely deep, motionless abyss. The model consists of eight sigma levels ("sigma" in this usage is a generalized vertical coordinate that has nothing to do with density, and is denoted " $s$ ") within the active upper layer, plus the surface mixed layer. Both the total upper layer thickness and the surface mixed layer depth vary in time and space, determined by the wind and buoyancy forcing, and the eight sigma layers are specified fractions of the remaining thickness. The point of this formulation is to retain good vertical resolution following the base of the mixed layer where it is important to closely resolve vertical exchanges of heat and momentum. For this reason the model is highly computationally efficient and has been used in numerous simulations of the Pacific and other regions.

The model domain is the tropical Pacific with solid walls at $30^{\circ} \mathrm{S}$ and $30^{\circ} \mathrm{N}$ and no opening through the Indonesian archipelago, but otherwise realistic east and west coasts. A stretched grid is used in which the zonal spacing is smallest at the east and west edges ( $\Delta x$ about $50 \mathrm{~km})$ and largest in midbasin $(\Delta x$ about $120 \mathrm{~km})$ while the meridional spacing is smallest within $10^{\circ} \mathrm{N}$ and $\mathrm{S}$ (where $\Delta y$ is about $40 \mathrm{~km}$ ) and largest at the poleward edges ( $\Delta y$ increases to about $220 \mathrm{~km}$ ). The time step is $1 \mathrm{~h}$. The model is initialized with the Levitus (1982) mean temperatures. Relaxation to the Levitus climatological annual cycle temperatures becomes progressively stronger poleward of $\pm 20^{\circ}$ latitude to suppress coastal Kelvin waves that would otherwise contaminate the solution given these unrealistic poleward boundaries. Bulk formulas are used for latent, longwave, and sensible heat fluxes, according to the formulation of Seager et al. (1988), which requires heat flux forcing through specified wind stresses and clouds only. The equation of state is a linear function of temperature, with no effect of salinity, although the mean salinity distribution and its variations are likely to be an important contribution to density in the tropical Pacific (Murtugudde and Busalacchi 1998; Ji et al. 2000; Kessler 1999).

The model run diagnosed here was forced with a wind stress climatology constructed from the 1991-2000 ERS winds described in section $2 \mathrm{~b}$, and climatological clouds based on the 1983-94 International Satellite Cloud Climatology Project (ISCCP) C2 product (Rossow and Schiffler 1991). The model was run for 10 years, and all results shown here are from model year 10 . To test that the model is fully spun up in 10 years, it was run 
with the same winds for 40 years, and annual averages were found to be nearly constant after about year 7 .

All quantities from the model were found from 5-day sampling of model output during year 10. Products and derivatives were found from this sampling exactly as formulated in the model (Gent and Cane 1989) and were then vertically integrated and time averaged. Friction terms were found by comparing model velocities before and after calling the friction subroutines each time step.

\section{d. Definitions of currents}

The usual (and most realistic) definition of a current specifies boundaries (a latitude and a depth or density range) and then defines, say, a westward current as all negative zonal flow within those bounds. Here, where we are interested in comparing observed and modeled currents with the wind-driven Sverdrup transports, it is only the vertically integrated transports that are relevant. Thus, velocities are first vertically integrated and timeaveraged, then each current is defined as the appropriately signed depth-integrated transport $\left(\int u d z\right)$ within latitude boundaries, which is directly comparable to the Sverdrup transport derived from the wind. The observed transport of a particular current produced by this procedure is, in general, smaller than the total transport that would be obtained by the usual definition, because it does not take into account the possibility of two or more currents occurring in different vertical ranges at the same horizontal location. For example, vertical-meridional sections of zonal current (Fig. 2) show a somewhat more complex structure than the vertically integrated zonal transports (Fig. 3, top). Here, we define the currents only as they appear in Fig. 3 (top), which omits, for example, some SEC flow that overlies the EUC (similarly, that part of the SEC reduces the eastward transport on the equator). Since the vertically integrated transports still largely correspond to the well-known currents, we will refer to these transports with the usual name of the current, but flagged with a superscript $z$. These transports are $\mathrm{SEC}(\mathrm{S})^{z}$, defined as westward transport within $8^{\circ} \mathrm{S}-2^{\circ} \mathrm{S} ; \mathrm{SEC}(\mathrm{N})^{z}$, westward transport within $1^{\circ} \mathrm{N}-5^{\circ} \mathrm{N}$; and $\mathrm{EUC}^{z}$, eastward transport within $3^{\circ} \mathrm{S}-$ $2^{\circ} \mathrm{N}$. These definitions produce comparable quantities from the ADCP observations, from the OGCM, and from the Sverdrup circulation (Fig. 3); meridionally integrated totals are shown in Fig. 4. It would be desirable to also analyze the North Equatorial Countercurrent (NECC) but, since it lies partly outside the region sampled by the ADCP (Fig. 3, top), evaluation of its transport is not possible.

\section{Dynamics}

The vertically integrated, time-mean momentum equations can be written

$$
\begin{aligned}
& A^{x}-f V=-P_{x}+\tau^{x}+F^{x} \\
& A^{y}+f U=-P_{y}+\tau^{y}+F^{y},
\end{aligned}
$$

where uppercase symbols indicate vertically integrated quantities, subscripts indicate partial differentiation, and factors of the background density $\rho_{0}$ have been dropped for simplicity of notation. In conventional notation, $(U$, $V)$ are the transport components, $f$ is the Coriolis parameter, $P$ is the integrated pressure, and $\tau$ is the wind stress; $\mathbf{A}=\left(A^{x}, A^{y}\right)=\int \boldsymbol{\nabla} \cdot(\mathbf{u} h \mathbf{u}) d s$ are the advective terms (in flux form, see section $4 \mathrm{~d}$ ) and $\mathbf{F}=\left(F^{x}, F^{y}\right)$ are the (combined) friction terms (see section $2 \mathrm{c}$ ). The vertically integrated mean continuity equation is

$$
U_{x}+V_{y}=0 \text {. }
$$

A common linearization of (1) retains only the Coriolis, pressure gradient, and wind stress terms:

$$
\begin{aligned}
-f V & =-P_{x}+\tau^{x} \\
f U & =-P_{y}+\tau^{y} .
\end{aligned}
$$

Taking the curl of (3), substituting from (2) gives the meridional transport associated with the Sverdrup balance:

$$
\beta V=\operatorname{curl}(\tau)
$$

The Sverdrup zonal transport is found from (2), using (4) for $V$ and integrating from the eastern boundary:

$$
U=-\frac{1}{\beta} \int_{\mathrm{EB}}^{x} \operatorname{curl}(\tau)_{y} d x+U_{\mathrm{EB}}(y),
$$

where $U_{\mathrm{EB}}(y)$ is the eastern boundary value (see the appendix). The success of the Sverdrup balance in explaining major features of the ocean circulation reflects the fundamental importance of the vorticity in the lowfrequency dynamics.

In section 4 we will diagnose the importance of the advective and friction terms in the ocean GCM. The model's vertically integrated momentum balance is principally among the Ekman and geostrophic terms (3), and the advective and friction terms are small compared to the leading Coriolis, pressure gradient and wind stress terms in (1). However, at the same time the model currents and pressure gradients will be seen to differ substantially from those predicted by the Sverdrup balance. Considering the effects of the advective and friction terms on the vorticity balance shows how this comes about.

Since the model velocity is known, (1) can be rearranged so the advective and friction terms appear as analogs to forcing terms, defining a generalized stress $\tau^{*} \equiv \tau+\tau^{\prime}+\tau^{\prime \prime}$, where $\tau^{\prime} \equiv-\mathbf{A}$ and $\tau^{\prime \prime} \equiv \mathbf{F}$. Then (1) are rewritten as

$$
\begin{aligned}
-f V & =-P_{x}+\tau^{* x} \\
f U & =-P_{y}+\tau^{* y},
\end{aligned}
$$

which have the same form as the linearized set (3). 

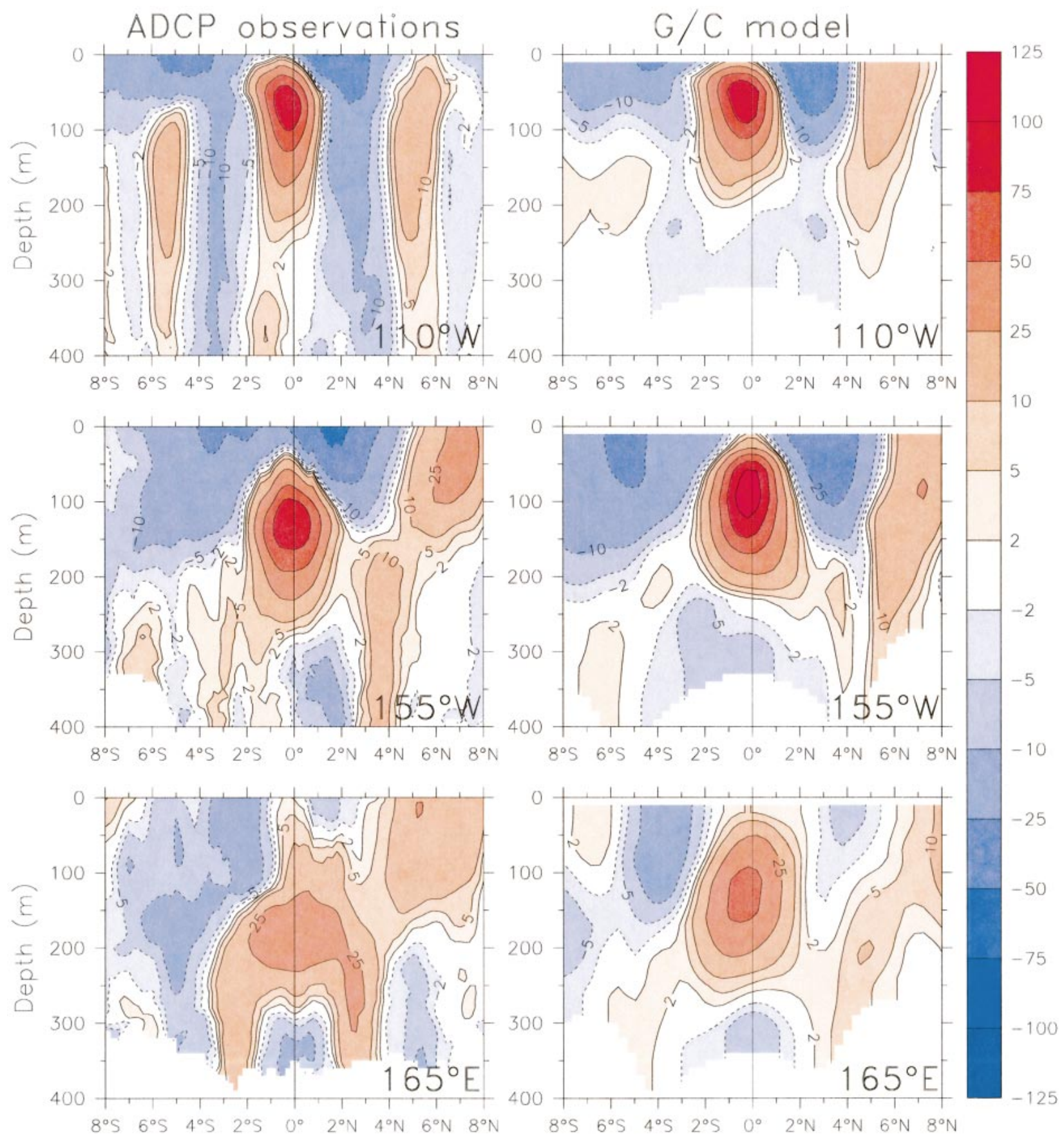

FIG. 2. Meridional-vertical sections of mean zonal current at three representative longitudes, estimated (left) from ADCP data and (right) from the model. All six panels have the same contour interval: every $25 \mathrm{~cm} \mathrm{~s}^{-1}$ from -125 to $125 \mathrm{~cm} \mathrm{~s}^{-1}$, with supplementary contours at $\pm 2,5$, and $10 \mathrm{~cm} \mathrm{~s}^{-1}$. For the ADCP observations, typically each latitude-depth value plotted is the mean of 30-50 observations; blank areas at the bottom of these plots indicates locations with less than 20 observations. Blank areas at the bottom of the model panels indicate the model interface with the motionless abyss.

Taking the curl of (6) leads to a balance of the form (4) and (5), with $\tau$ replaced by $\tau^{*}$, in which the effects of the advective and friction terms are evaluated through their modification of the vorticity. This procedure allows all three "forcing" terms to be studied individually and compared, and their effects linearly added. Of course, the definition of $\tau^{*}$ is just a rearrangement of (1), so $U$ and $V$ obtained from (6) recover the original $U$ and $V$. For any steady vertically integrated system (1) and (2), the equivalents of (4) and (5), with $\tau$ replaced by $\tau^{*}$, are always true. We emphasize that this is not a method to get solutions to (1), but simply to diagnose the im- 


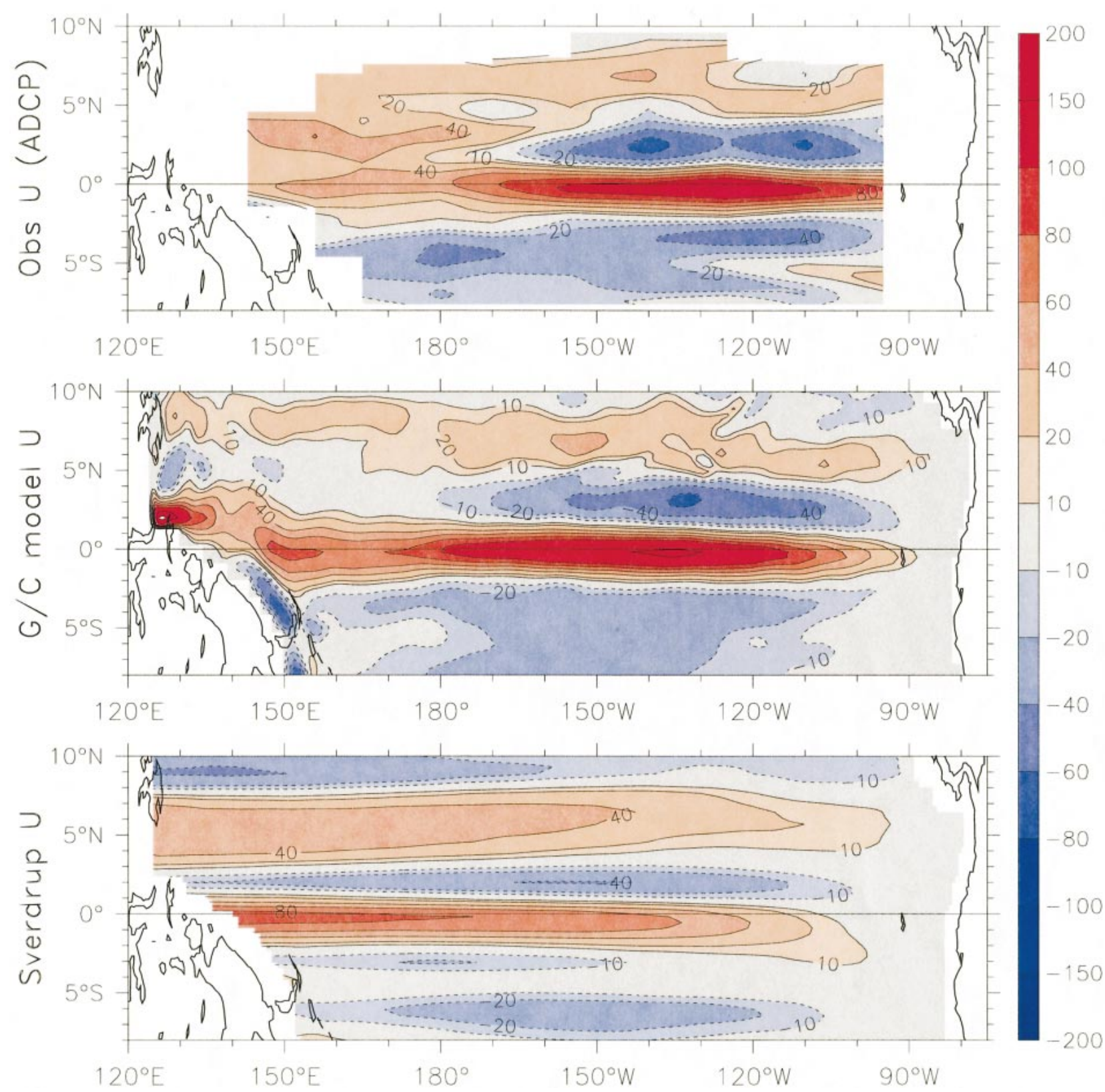

FIG. 3. Vertically integrated zonal transport/unit width $\left(\mathrm{m}^{2} \mathrm{~s}^{-1}\right.$ ) from (top) ADCP observations, (middle) model, and (bottom) the Sverdrup balance [Eq. (5)]. Red colors indicate eastward transport, blue colors westward. The colored area in the top panel shows areas sampled by ADCP observations. Observed and model transports are integrated from the bottom of the ADCP sampling and the model, respectively; about $400 \mathrm{~m}$ in each case.

portance of the terms in the context of the vorticity balance. What is found by this manipulation is that the importance of the second-order terms comes through their derivatives; in particular, their effect on the zonal current is realized in $d\left[\operatorname{curl}\left(\tau^{*}\right)\right] / d y$, and these derivatives have quite different spatial patterns than the terms themselves. Although it will be seen that in the model solution the advective terms $A^{x}$ and $A^{y}$ in (1) have similar magnitudes, $A^{x}$ has much greater significance because in forming the curl, $A_{y}^{x} \gg A_{x}^{y}$.
It is assumed in the above that vertical integrations are carried to the bottom of the ocean or to a depth where the velocity $(u, v, w)$ and the stress are all zero. In the model the integrations are carried over the full model thickness (which averages $353 \mathrm{~m}$ within $8^{\circ} \mathrm{S}-$ $10^{\circ} \mathrm{N}$ ), satisfying this criterion. The ADCP mean bottom depth within $8^{\circ} \mathrm{S}-10^{\circ} \mathrm{N}$ is $396 \mathrm{~m}$, and integrations are made over the full range of available data. We have no way to evaluate the impact of flows below this depth, which remains a source of unknown error in the results. 


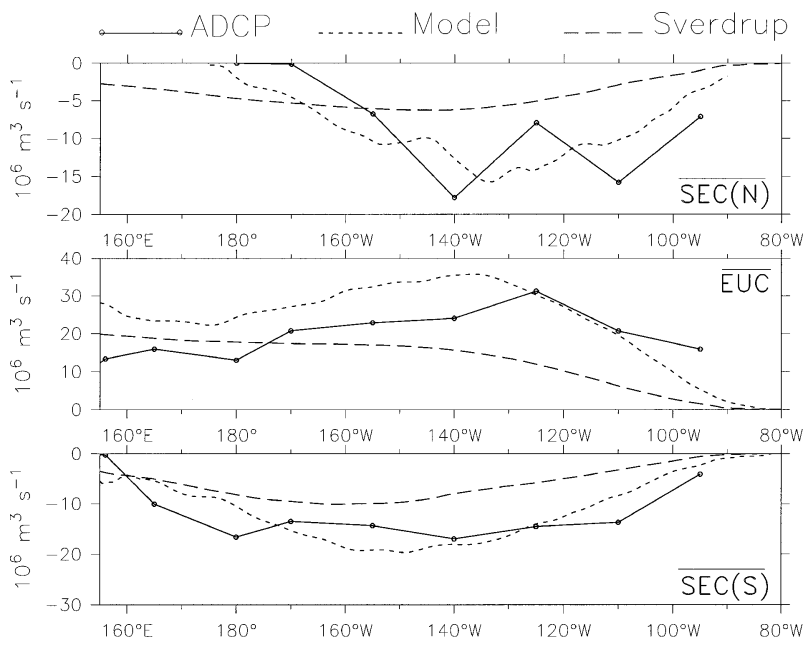

FIG. 4. Transports of zonal currents $\left(10^{6} \mathrm{~m}^{3} \mathrm{~s}^{-1}\right)$ integrated over the areas of either positive or negative transports shown in Fig. 3 (see section 2d): (top) SEC $(\mathrm{N})^{z}$, defined as westward integrated transport between the equator and $5^{\circ} \mathrm{N}$; (middle) $\mathrm{EUC}^{z}$, defined as all eastward transport within $3^{\circ} \mathrm{S}-2^{\circ} \mathrm{N}$; (bottom) $\mathrm{SEC}(\mathrm{S})^{z}$, defined as all westward transport within $8^{\circ}-2^{\circ} \mathrm{S}$. In each case three curves are shown: measured ADCP transport (solid line with dots indicating the longitudes of the sections), Sverdrup transport (dashed line) [Eq. (5)], and model transport (dotted line). The vertical scale is different for each current system.

\section{Results}

\section{a. The observed currents}

Vertical sections of measured (ADCP) mean zonal current at three representative longitudes show the SEC split into a northern and southern branch, and draped across the EUC (Fig. 2, left panels). At $110^{\circ} \mathrm{W}$ in the eastern Pacific, the EUC is found at depth 50-100 m in the shallow thermocline (Johnson et al. 2002), and mean currents near the surface at the equator are about zero (Fig. 2, top left). Both branches of the SEC appear to extend well below the thermocline at $2^{\circ}-4^{\circ} \mathrm{N}$ and $\mathrm{S}$; indeed, a geostrophic estimation of these deep currents based on the associated CTD data (not shown) indicates westward flow to at least $600 \mathrm{~m}$ (relative to a 900-m reference level). It is not known why the SEC occurs so deep in the east; however, the large transports found by vertically integrating these flows are consistent with the dynamical picture developed below. In the central Pacific, the thermocline (not shown) and EUC are found somewhat deeper (Fig. 2, middle). The SEC is thin but strong on the equator above the EUC and both branches are well developed above the thermocline. At the surface, fastest westward flow is found at $\pm 2^{\circ}-3^{\circ}$ latitude in both hemispheres. North of the equator, strong horizontal shears are seen between the $\operatorname{SEC}(\mathrm{N})$ and both the EUC and NECC, but the SEC $(\mathrm{S})$ gradually weakens to the limit of the present data at $8^{\circ} \mathrm{S}$. In the west, the EUC core is found relatively deep ( $200 \mathrm{~m}$ : Fig. 2, bottom) but, perhaps surprisingly, the SEC at the equator is thin and weak in the mean. Velocities above the EUC core are known to be highly variable in this regime where the trade winds are weak and frequently interrupted by westerlies (Cronin et al. 2000), and the mean velocities estimated from the ADCP data may be aliased by this variability. The NECC is found relatively close to the equator in the west, which tends to squeeze and reduce the $\operatorname{SEC}(\mathrm{N})$.

The vertically integrated transports found from the ADCP data (Fig. 3, top) are strongly eastward on the equator with a maximum near $125^{\circ} \mathrm{W}$, but these eastward transports drop by about $1 / 3$ in the west. Both branches of the (vertically integrated) $\mathrm{SEC}^{z}$ also have maxima in the east-central Pacific and both are strongest near $\pm 3^{\circ}$ $4^{\circ}$ latitude. Although the surface flow at $2^{\circ}-3^{\circ} \mathrm{N}$ is westward to at least $155^{\circ} \mathrm{E}$, the vertically integrated transport is westward only east of $170^{\circ} \mathrm{W}$, because farther west the surface flow is weak (e.g., Fig. 2, bottom left) and is underlain by the eastward-flowing northern subsurface countercurrent.

\section{b. Sverdrup balance}

The pattern of ERS-derived wind stress curl (Fig. 5) is largely familiar (e.g., Landsteiner et al. 1990), with

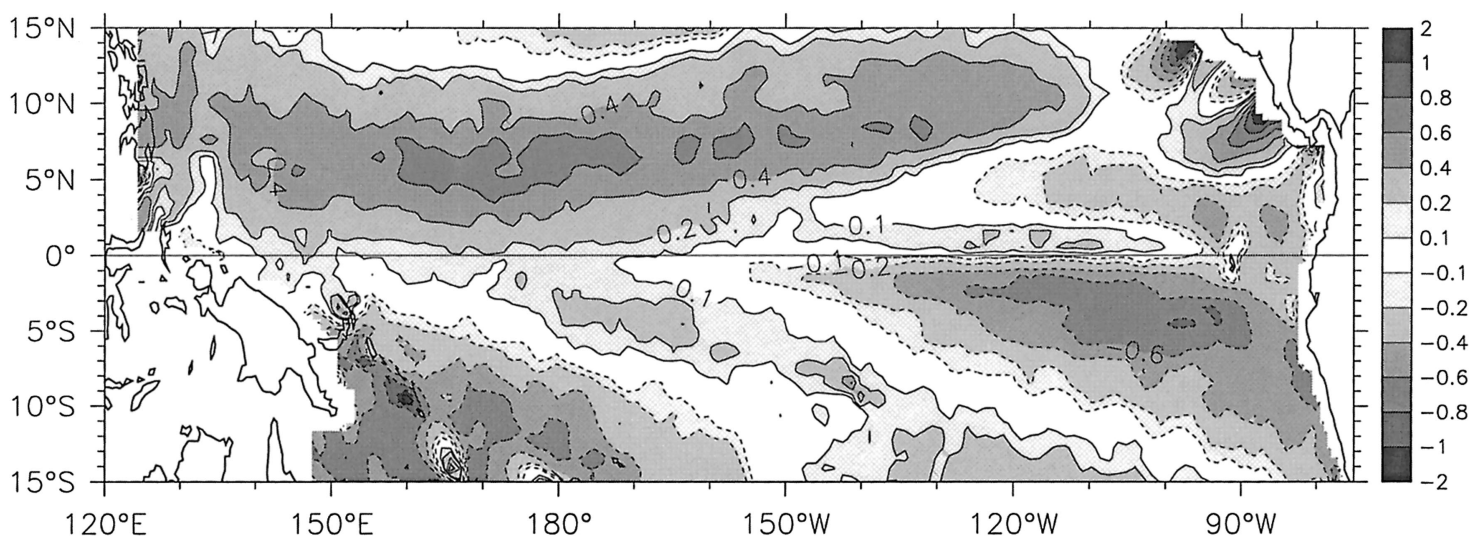

FIG. 5. Mean wind stress curl $\left(10^{-7} \mathrm{~N} \mathrm{~m}^{-3}\right)$ from ERS scatterometer winds during 1991-2000. Both positive and negative values of curl greater than $0.1 \times 10^{-7} \mathrm{~N} \mathrm{~m}^{-3}$ are shaded. 
the Tropics dominated by the band of positive curl along $5^{\circ}-10^{\circ} \mathrm{N}$ where the northeast trades build to the north from the ITCZ tradewind minimum. However, the advent of satellite scatterometer winds has revealed a new element to the curl forcing, seen as a narrow strip of positive curl just north of the equator from about $150^{\circ}-$ $100^{\circ} \mathrm{W}$ (Fig. 5). This strip is usually not apparent in ship wind or reanalysis products, but is a consistent feature of satellite winds [e.g., in the QuikSCAT winds shown in Chelton et al. (2001)]. It is a consequence of SSTinduced modification of the planetary boundary layer (PBL) in the southeasterly regime over the eastern equatorial Pacific (Wallace et al. 1989). Cool SST in the east Pacific cold tongue tends to stabilize the PBL and thus isolate it from the free atmosphere above; as a result, surface wind speeds over the cold tongue are lower by about $30 \%$ in the cool half of the year. As the southeasterlies cross the SST front north of the cold tongue, warm SST induces convection that mixes momentum down to the surface, increasing the wind speed (but not changing the direction). Wallace et al. (1989) showed that this results in a wind divergence, and Chelton et al. (2001) showed that because the southeasterlies cross the front at an angle, a curl signature as well. The result is a strip of positive curl north of the equator (Fig. 5).

When (5) is used to estimate the Sverdrup zonal transport from the curl shown in Fig. 5, the strip of positive curl produces an eastward jet along the equator (the $\left.\mathrm{EUC}^{z}\right)$ and a westward flow [the $\mathrm{SEC}(\mathrm{N})^{z}$ ] from $1^{\circ}-3^{\circ} \mathrm{N}$ (Fig. 3, bottom). Although the curl values themselves are relatively small, their meridional derivatives are not and, because the strip is zonally oriented, it makes a large contribution to the zonal integral (5). Earlier calculations of the Sverdrup transport, based on ship winds, showed only weak transports in the region (Kessler and Taft 1987; Godfrey 1989; Landsteiner et al. 1990), without any sign of a distinct $\mathrm{EUC}^{z}$ or an $\operatorname{SEC}(\mathrm{N})^{z}$. The effect of the SST-modified wind speed is to produce, through Sverdrup dynamics, a significantly more realistic circulation than was possible before; in particular the scatterometer winds imply a clear $\mathrm{EUC}^{z}$ and $\mathrm{SEC}(\mathrm{N})^{z}$ (Fig. 3). However, even with these improvements, the Sverdrup circulation has first-order differences from that observed; the transports of the $\operatorname{SEC}(\mathrm{S})^{z}$ and $\mathrm{SEC}(\mathrm{N})^{z}$, as well as the $\mathrm{EUC}^{z}$, are about one-half of the measured values (Fig. 4). Further, the observed $\operatorname{SEC}(\mathrm{N})^{z}$ is found only east of $180^{\circ}$, while the corresponding Sverdrup flow in this region extends all the way to the western boundary, and the observed $\operatorname{SEC}(\mathrm{S})^{z}$ is strong close to the equator where the Sverdrup flow is weak (Fig. 3). Similarly, the Sverdrup transport along the equator grows in magnitude all the way west to the New Guinea coast, whereas the observed (and modeled) $\mathrm{EUC}^{z}$ has its maximum near $140^{\circ} \mathrm{W}$ and decreases in the west. The remainder of this paper seeks to understand the reasons for these discrepancies and diagnose the dynamics responsible for the actual currents.

\section{c. OGCM solution}

The roughly semiannual ADCP sampling is too sparse to estimate the advection terms of the momentum balance [but see Johnson and Luther (1994), who worked from monthly sampling], so we turn to the ocean GCM, described in section $2 \mathrm{c}$ and driven by the average annual cycle of the same winds that produced the Sverdrup circulation discussed above, for additional insight. The model vertically integrated zonal currents agree more closely with the observations than do those predicted by the Sverdrup relation (Fig. 3), and the same is true for the zonal transports integrated over the individual currents (Fig. 4). The model SEC(N)z has a zonal extent $\left(180^{\circ}\right.$ to $\left.90^{\circ} \mathrm{W}\right)$, which is like the observed current and more realistic than the Sverdrup $\mathrm{SEC}(\mathrm{N})^{z}$ (Fig. 3). Model SEC $(\mathrm{N})^{z}$ transport is also a major improvement over the Sverdrup representation (Fig. 4). Along the equator, the model EUC $^{z}$ has its eastward maximum at about $140^{\circ} \mathrm{W}$ and is reduced by a factor of about $50 \%$ in the west, like the observations but unlike the Sverdrup depiction which increases monotonically westward. The model SEC $(\mathrm{S})^{z}$ is realistically strong close to the equator and its transport is similar to the observed $\operatorname{SEC}(\mathrm{S})^{z}$, while the Sverdrup estimate differs in both aspects. For all three current systems, the Sverdrup representation has typically half the observed transport, while the model transports are similar in magnitude and spatial pattern to those observed (Fig. 4).

The most notable discrepancy between the modeled and observed transports is at $3^{\circ}-6^{\circ} \mathrm{N}$ west of the date line, where the model has near-zero zonal transport but the observations show a relatively strong eastward flow (Fig. 3). Two possibly related problems contribute to this. First, the model NECC is shifted north of the observed position in the west (Fig. 2, bottom panels, and Fig. 3) for unknown reasons. Second, the model simulates only weak subsurface countercurrents (Tsuchiya Jets; Rowe et al. 2000), which are the eastward lobes flanking the EUC below the thermocline at about $\pm 2^{\circ}-$ $3^{\circ}$ latitude at $165^{\circ} \mathrm{E}, \pm 3^{\circ}-4^{\circ}$ at $155^{\circ} \mathrm{W}$, and $\pm 5^{\circ}-6^{\circ}$ at $110^{\circ} \mathrm{W}$ (Fig. 2, left panels). The weak model Tsuchiya jets are barely evident in the $2 \mathrm{~cm} \mathrm{~s}^{-1}$ contours in Fig. 2 (right panels), and are too far poleward in the west. Donohue et al. (2002) suggested on the basis of comparing several OGCMs that very high vertical resolution was key to proper simulation of these features, and the present model certainly fails that test. Despite these discrepancies, the near-equatorial transports reproduced by the model are considerably more realistic than the Sverdrup solution, which argues that examination of the model momentum terms that modify the linear Sverdrup circulation will be illuminating.

\section{d. The role of the nonlinear terms: Momentum balance}

The model equations are written in flux form, which is the sum of the continuity equation multiplied by the 


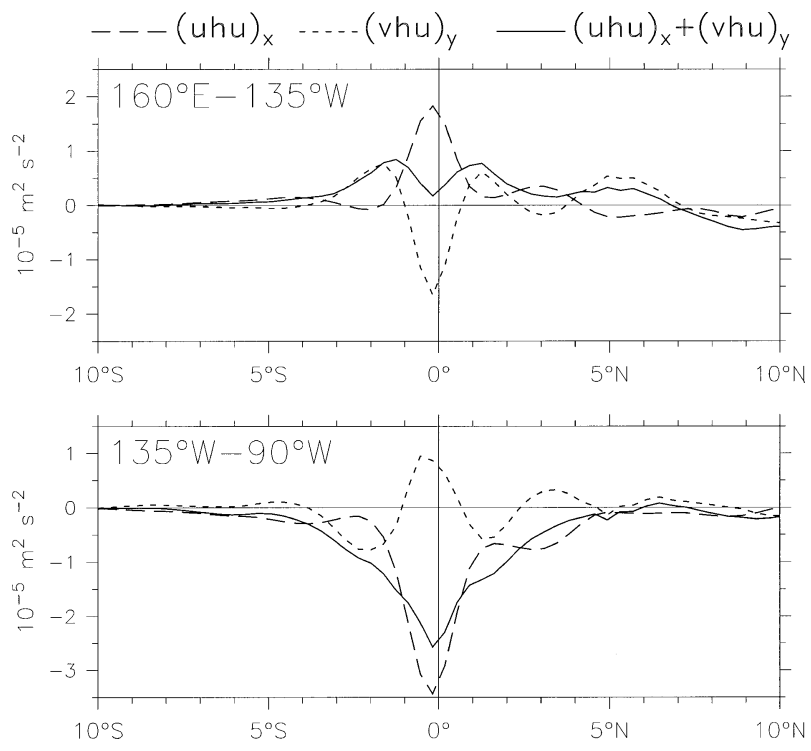

FIG. 6. Divergence of zonal momentum flux $\left(10^{-5} \mathrm{~m}^{2} \mathrm{~s}^{-2}\right)$, showing the total $\left[\boldsymbol{\nabla} \cdot(\mathbf{u} h u)\right.$, solid line], and the zonal $\left[(u h u)_{x}\right.$, dashed line] and meridional $\left[(v h u)_{v}\right.$, dotted line] divergences. Zonal averages over the west-central $\left(160^{\circ} \mathrm{E}-135^{\circ} \mathrm{W}\right)$ and eastern $\left(135^{\circ}-90^{\circ} \mathrm{W}\right)$ are shown in the top and bottom panels, respectively. Longitude $135^{\circ} \mathrm{W}$ is a natural break in the pattern (e.g., Fig. 7b) because it is the maximum of the $\mathrm{EUC}^{z}$ where the zonal divergence changes sign.

horizontal velocity $\mathbf{u}=(u, v)$, added to the momentum equations multiplied by the layer thickness $h$ : the advective terms (which are assumed to be vertically integrated and time-averaged) are thus $\mathbf{u} \nabla \cdot(\mathbf{u} h)+h \mathbf{u}$. $\boldsymbol{\nabla} \mathbf{u}=\boldsymbol{\nabla} \cdot(\mathbf{u} h \mathbf{u}) .\{$ Here the operator $\boldsymbol{\nabla} \equiv(\partial / \partial x, \partial / \partial y)$, since we are considering only the mean, vertically integrated balances, so the vertical terms that are included in the total advection $[\partial(w \mathbf{u}) / \partial s]$ integrate to zero. $\}$ In general, the parts of these terms involving gradients of $h(\mathbf{u u} \cdot \boldsymbol{\nabla} h)$ are smaller than the parts involving gradients of $\mathbf{u}$, especially in the zonal momentum equation.

The divergence of zonal momentum flux $[\nabla \cdot(\mathbf{u} h u)$, which we have called $A^{x}$, or $-\tau^{\prime x}$, in section 3] is due to zonal $\left[(u h u)_{x}\right]$ and meridional $\left[(v h u)_{y}\right]$ divergences (Fig. 6 shows these terms averaged over the eastern and central-western Pacific, respectively). Both these terms are primarily determined by the large-scale three-dimensional mean circulation: at the equator $u$ is eastward at thermocline level and small at the surface and is westward just off the equator (Fig. 2), while $v$ is equatorward in both hemispheres at EUC level and poleward in a thin layer at the surface. In the west, mass converges meridionally in a thick layer ( $s 0 \int v_{y} d s<0$ ), feeding the accelerating EUC, while in the east mass diverges closer to the surface as the EUC slows.

The classical picture (Fofonoff and Montgomery 1955; Robinson 1966; Gill 1975) is a two-dimensional $(y, z)$ section appropriate to the central and western Pacific, dominated by equatorward flow in a thick thermocline layer where the EUC is strong. Eastward momentum is fluxed equatorward by the meridional cir- culation: in the vertical integral the term $(v h u)_{y}$ is negative along the equator and positive just off the equator (dotted line in Fig. 6, top). This argument suggests that the advective terms represent an eastward tendency along the equator. However, we find two significant differences from this picture. First, in the eastern Pacific much of the EUC occurs in the Ekman-diverging layer near the surface, changing the sign of the vertically integrated term $(v h u)_{y}$ (dotted line in Fig. 6, bottom), indicating that $\mathrm{EUC}^{z}$ eastward momentum is fluxed poleward. [In addition, the meridional structure in the east is distorted because the meridional circulation is shifted southward by the mean southerly winds (Philander and Delecluse 1983; and see Kessler et al. 1998 for a description of this cell in the present model).] Second, and most important, the zonal divergence of zonal momentum flux $\left[(u h u)_{x}\right.$, dashed line in Fig. 6] is positive in the west and strongly negative in the east, reflecting the acceleration and deceleration of the EUC ${ }^{z}$, so the zonal term opposes the meridional term everywhere along the equator. In the west the two flux divergences nearly cancel (Fig. 6, top) but in the east the large zonal convergence dominates (Fig. 6, bottom).

The apparent conclusion from the momentum balance is that the advective terms serve as an eastward tendency in the eastern Pacific and as a small westward tendency in the central-western Pacific (solid lines in Fig. 6). This is of the correct sign to account for the larger eastern and smaller western EUC ${ }^{z}$ than is given by the linear (Sverdrup) terms but is inconsistent with the differences between the Sverdrup transports and the observed and modeled pattern of the $\operatorname{SEC}(\mathrm{N})^{z}$ or $\operatorname{SEC}(\mathrm{S})^{z}$, both of which are stronger in the east than the linear balance indicates (Fig. 3).

\section{e. The role of the nonlinear terms: Vorticity balance}

The nonlinear effects on vorticity are studied by considering the generalized stresses $\tau^{*}$ as in (6). In this manipulation of the momentum equations (1) the advective and frictional terms are defined as "stresses" $\tau^{\prime}$ and $\tau^{\prime \prime}$; the curl of each of these stresses (Fig. 7, left panels) and the zonal transports resulting from an integration of the form (5) (Fig. 7, right panels) are comparable in magnitude to those of the wind stress curl (Fig. 7, top panels). The sum down the left and right columns of Fig. 7 closely recovers the total model $\beta V$ and $U$, respectively, shown in the bottom panels. Since the sum $\tau^{*}$ and the operations in (4) and (5) are linear, the effects of wind forcing, advection, and friction on the total transports can be examined separately.

Although all of the advective terms are of comparable magnitude in the zonal and meridional momentum equations, in taking the curl, $\partial / \partial x$ of the meridional terms is much smaller than $\partial / \partial y$ of the zonal terms, so the meridional terms have little effect in the curl or zonal transport. In the east $\operatorname{curl}\left(\tau^{\prime}\right)$ is primarily due to the deceleration of the EUC ${ }^{z}: u u_{x}$ is negative (Fig. 6, bottom) so 

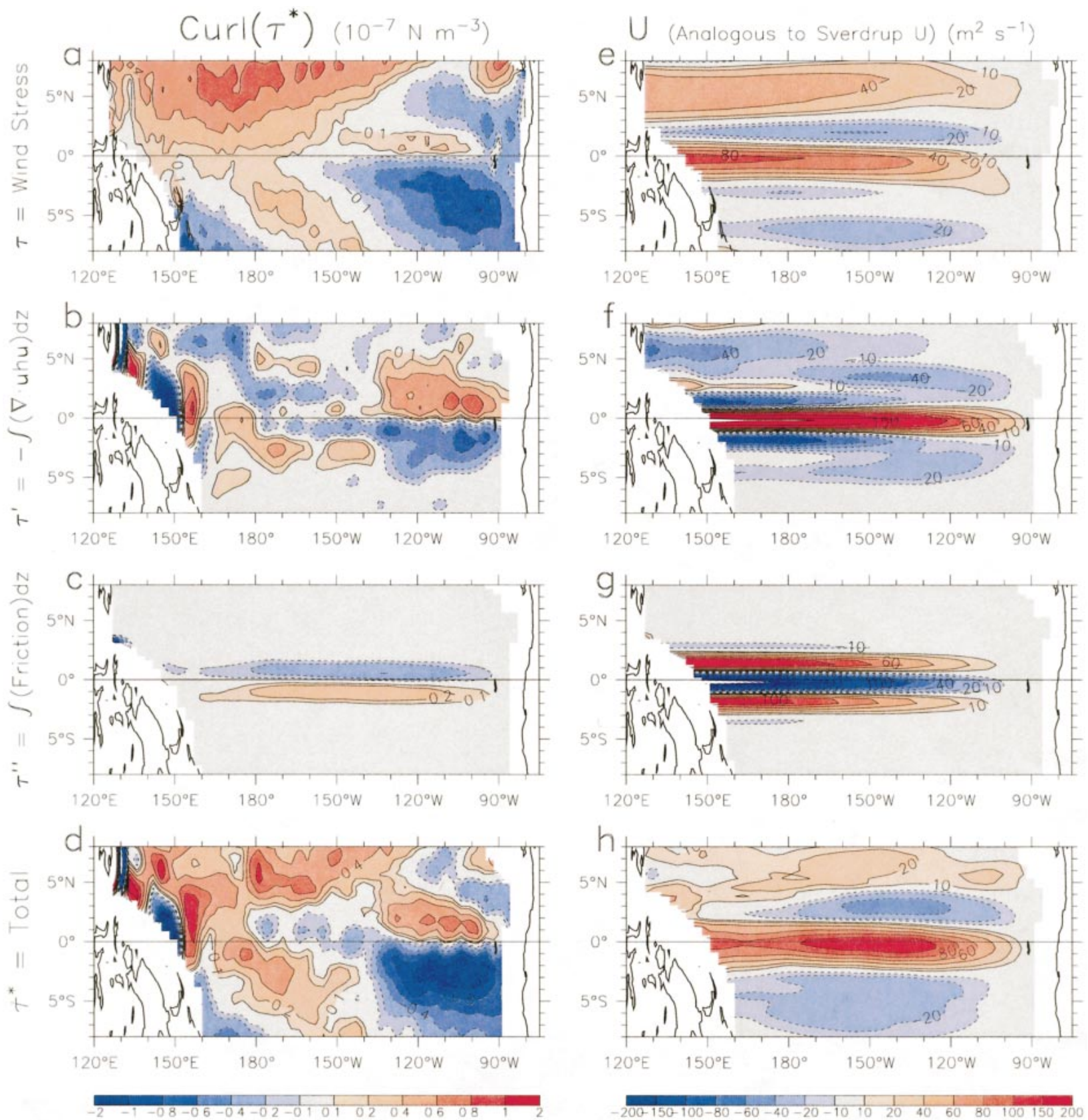

FIG. 7. (left) $\operatorname{Curl}\left(\tau^{*}\right)\left(10^{-7} \mathrm{~N} \mathrm{~m}^{-3}\right)$ and (right) zonal "transport" [Eq. (5)] $\left(\mathrm{m}^{-2} \mathrm{~s}^{-1}\right)$ for the elements of the generalized stress $\tau^{*}$ [see Eq. (6)]. Units and contour levels of all right panels and all left panels are the same (color scales at bottom). Red colors indicate positive curl or eastward transport; blue colors indicate negative curl or westward transport. Here (top) $\tau=$ wind stress; (second) $\tau^{\prime}=$ advection terms; (third) $\tau^{\prime \prime}=$ model friction; (bottom) total (sums of three upper panels).

$\tau^{\prime x}$ is positive, and $\operatorname{curl}\left(\tau^{\prime}\right)$ changes sign across the equator (Fig. 7b). Its magnitude is similar to, if not larger than, the wind stress curl (Fig. 7a). In the west there are smaller gradients of $\tau^{\prime x}$ (Fig. 6, top), and the pattern of $\operatorname{curl}\left(\tau^{\prime}\right)$ is muddled. Since the influences of the vorticity terms on zonal transport are realized by integrating their meridional derivatives westward (thus taking two meridional derivatives of the momentum terms shown in Fig. 6), it is the eastern signal (with its large gradient across the equator principally determined by $\mathrm{EUC}^{z}$ deceleration) that sets the large-scale pattern (Fig. 7b). When $\partial\left[\operatorname{curl}\left(\tau^{\prime}\right)\right] / \partial y$ is integrated westward, the advective terms are seen to have the effect of intensifying the mean vertically integrated currents, both the eastward $\mathrm{EUC}^{z}$ and the westward $\operatorname{SEC}(\mathrm{N})^{z}$ and $\operatorname{SEC}(\mathrm{S})^{z}$ (Fig. 7f). Physically, in the west-central Pacific cyclonic relative 


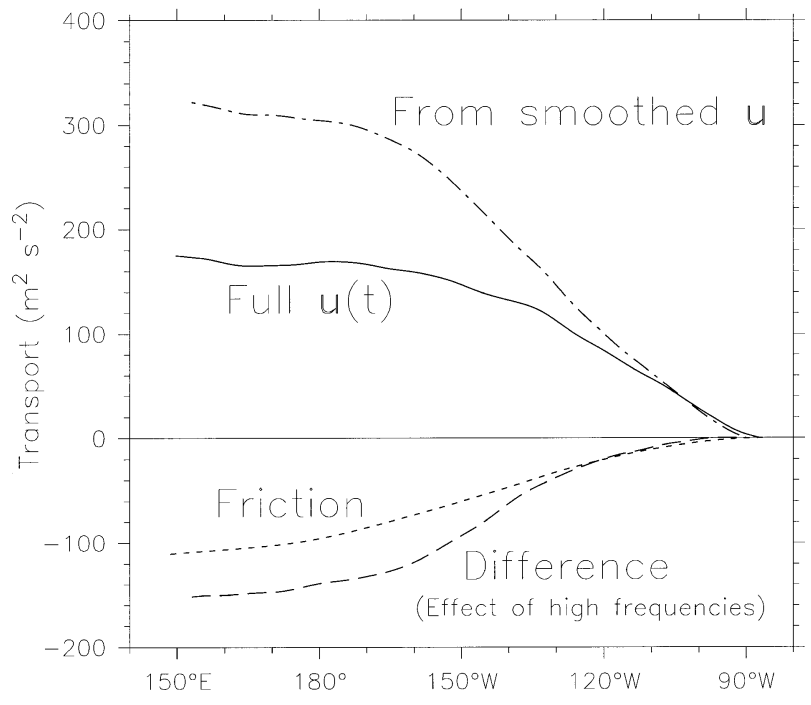

FIG. 8. Zonal transport/unit width $\left(\mathrm{m}^{-2} \mathrm{~s}^{-1}\right)$ along the equator due to the advection and friction terms. Lines labeled "Full u(t)" (solid) and "Friction" (dotted) are equatorial sections from Figs. 7f and 7g. Line labeled "From smoothed u" (dash-dot) shows transport from the advection terms calculated with temporally smoothed velocities (see section 4e), and the line labeled "Difference" (dashed) is the difference between this and the transport from the full time dependence of $\mathbf{u}$, which can be interpreted as the effect of high frequencies.

vorticity is generated by equatorward motion [because $f-u_{y}$ following a particle is nearly constant (Fofonoff and Montgomery 1955)], which is advected eastward and then converges as the EUC ${ }^{z}$ decelerates. Note that the negative and positive regions of $\operatorname{curl}\left(\tau^{\prime}\right)$ east of $135^{\circ} \mathrm{W}$ (Fig. $7 \mathrm{~b}$ ) represent cyclonic vorticity forcing (stretching) on both sides of the equator. The result of this augmention of cyclonic relative vorticity in the east is to intensify the $\mathrm{EUC}^{z}$ well east of the maximum zonal pressure gradient, and also to produce westward flows on its poleward flanks that are much stronger than predicted by the Sverdrup balance.

The role of time-dependent advection rectified into the mean can be estimated by using temporally smoothed velocities to recompute the advective terms, then $\operatorname{curl}\left(\tau^{\prime}\right)$, then the integral (5), and then differencing the results with those shown in Figs. $7 \mathrm{~b}$ and $7 \mathrm{f}$, which are calculated accounting for the full time dependence of all terms. A 35-day triangle filter was used, which primarily removes the tropical instability waves (TIW). These differences are similar in sign and spatial pattern to the frictional terms (Figs. 7c and 7g, discussed below), consistent with earlier studies (Bryden and Brady 1989) indicating that the role of TIW advection is like a friction and acts to weaken the EUC and spread its eastward momentum to its flanks. Thus while total advection amplifies the mean currents as described above, the fluctuating part of these terms counters their overall tendency and reduces the net advective influence. The zonal transport associated with the full time-dependent advection terms (Fig. 7f, and solid line in Fig. 8) is smaller by about half than the corresponding quantity found from time-smoothed velocities (dash-dot line in Fig. 8). This means that using an estimate of mean or climatological velocities (such as might be available from the ADCP observations), or even monthly averages, to compute the advective terms would overestimate their effect on the circulation by a large factor.

The effect of friction in the vorticity balance is straightforward. The vertically integrated mean friction terms themselves are quite small (up to about 1/10 the size of the wind stresses), and mainly represent a damping of the $\operatorname{EUC}^{z}$ [in (1), mean $F^{x}$ is negative along the equator and $F^{y}$ is very small everywhere in the interior]. Thus, in taking the curl of $\tau^{\prime \prime}=\mathbf{F}$, the major term is $-\partial \mathbf{F}^{x} / \partial y$, which is positive just south of the equator and negative just north (Fig. 7c). The frictional curl maxima occur where the undercurrent is maximum in the central Pacific, and their magnitude is similar to that of the equatorial wind stress curl (Fig. 7a). In integrating $\partial\left[\operatorname{curl}\left(\tau^{\prime \prime}\right)\right] / \partial y$ westward as in $(5)$, the frictional effects on zonal transport are westward tendencies along the equator and eastward tendencies on the flanks of the $\mathrm{EUC}^{z}$, which is the intuitively expected damping effect of friction on the equatorial jet resulting in transfer of eastward momentum to the flanks, also damping the $\operatorname{SEC}(\mathrm{N})^{z}$ and $\operatorname{SEC}(\mathrm{S})^{z}$. Another way to say this is that friction reduces the relative vorticity $\left(-u_{y}\right)$ between the $\mathrm{EUC}^{z}$ and the SEC ${ }^{z}$ branches. The magnitude of the zonal transport associated with the friction terms is comparable to the wind-driven eastward Sverdrup transport in the east and central Pacific, and is larger than the wind-driven term in the west (cf. Figs. 7e and 7g).

Since the effects of friction and (total) advection have opposite signs (Figs. 7b and 7c), their zonal integrals tend to cancel in the far west. Figure 8 shows that the advective influence on zonal transport dominates east of $150^{\circ} \mathrm{W}$, west of which the damping effect of friction continues to increase. The result is that by the time the integrations reach the western boundary, the difference of total $U$ from the linear Sverdrup transport is smaller than anywhere in mid basin.

\section{Discussion}

A new equatorial Pacific climatology of directly measured zonal velocity (Johnson et al. 2002) resolves the near-equatorial mean structure of the South Equatorial Current on both sides of the equator across the Pacific. Westward zonal speeds are largest close to the equator $\left( \pm 2^{\circ}-3^{\circ}\right.$ latitude) in both hemispheres, resulting in high meridional shears (Fig. 2). Vertically integrated zonal transports are largest in the east-central Pacific near $140^{\circ}-110^{\circ} \mathrm{W}$ for both branches of the $\mathrm{SEC}^{z}$ and for the $\mathrm{EUC}^{z}$ (Fig. 3, top), with magnitudes of 15-25 Sv (Sv $\equiv 10^{6} \mathrm{~m}^{3} \mathrm{~s}^{-1}$ ) (Fig. 4).

The Sverdrup balance has been used to interpret the circulation of the tropical Pacific for more than 50 years (Sverdrup 1947; Meyers 1980; Godfrey 1989; Land- 
steiner et al. 1990; Fine et al. 2001) with considerable success and, in addition, has been the foundation for many diverse modeling efforts. However, when ship wind or assimilation products are used to compute the Sverdrup transports, the near-equatorial zonal transports are found to be very weak (e.g., Kessler and Taft 1987), unlike the observations reported here. In particular the $\operatorname{SEC}(\mathrm{N})^{z}$ and $\mathrm{EUC}^{z}$ are weak or absent from such calculations.

The advent of satellite scatterometer winds has revealed a new element of the wind stress curl forcing due to air-sea interaction in the eastern Pacific. As southeasterly trade winds cross the SST front north of the east Pacific cold tongue, warm SST induces vertical mixing that increases the surface wind speed (Wallace et al. 1989); since the winds cross the front at an angle, a systematically positive curl signature results (Chelton et al. 2001). This feature appears in the scatterometer winds as a strip of positive mean curl along about $1^{\circ} \mathrm{N}$ (Fig. 5). Although values of curl in the strip are not large, their meridional derivatives are significant and, since the Sverdrup zonal transport is the zonal integral of $\partial[\operatorname{curl}(\tau)] / \partial y$, this is sufficient to produce a qualitatively different, and more realistic, flow field than has been possible with in situ wind products. When scatterometer winds that include this strip (either from ERS or QuikSCAT) are used to estimate the Sverdrup transport, the EUC ${ }^{z}$ and a distinct $\mathrm{SEC}(\mathrm{N})^{z}$ are seen (Fig. 3, bottom). Remarkably, these currents are thus found to be partly due to the sharp SST front and its consequences on the planetary boundary layer of the eastern Pacific, whose effects are spread across the basin by Rossby wave radiation. In diagnosing the equatorial current structures, it is essential to study a wind field that includes these effects, and among presently available wind products, only the scatterometer winds suffice. It is likely that the coarse spatial resolution of gridded ship-based and assimilation wind products is the reason why the narrow strip of positive curl has not been previously noted.

Although the use of scatterometer winds results in a qualitative improvement in the realism of the linear Sverdrup depiction of tropical Pacific currents, significant differences remain between the Sverdrup solution and the observed transports. Along the equator, the Sverdrup transport grows monotonically to the west, whereas the observed transport is maximum in the east-central Pacific and decreases by a factor of at least 2 in the far west (Fig. 3, top). The Sverdrup $\mathrm{SEC}(\mathrm{N})^{z}$ also extends much farther west than observed, and the Sverdrup $\mathrm{SEC}(\mathrm{S})^{z}$ is much too weak near the equator. Sverdrup transports integrated over each current are only about half of the observed totals (Fig. 4). Therefore the role of nonlinear terms is considered, based on an OGCM solution, forced with the same (ERS) winds that were used to produce the Sverdrup estimates. The model solution gives a much more realistic representation of the observed currents (Fig. 3, middle, and Fig. 4).
The model vertically integrated momentum balance is nearly linear, with the advective and frictional terms generally an order of magnitude smaller than the linear terms that make up the Sverdrup balance. The only place where the advective terms are comparable to the wind stress is narrowly along the equator east of about $120^{\circ} \mathrm{W}$, and the friction terms are several times smaller than that. However, these small terms are seen to be a principal determinant of the circulation across the basin within at least $\pm 3^{\circ}$ latitude when diagnosed in the framework of the vorticity balance (Fig. 7) because (meridional) derivatives of these terms are large near the equator. This diagnosis is accomplished by rearranging the momentum equations (1) so that the advective and frictional terms appear as analogs to forcing terms, defining a generalized stress that includes the nonlinearities (6). Taking the curl of the rearranged momentum equations eliminates the pressure and gives an expression analogous to the Sverdrup balance (4) for the meridional transport, but including the effects of the nonlinear terms through their curl. An expression for these effects on zonal transport is found by zonally integrating the meridional derivative of the total curl, again in analogy to the Sverdrup zonal transport (5). The advantage of this manipulation is that the effects of wind stress, momentum advection, and friction can be examined separately, while their sum recovers the model total meridional and zonal transport. By this means, the characteristics of the equatorial current system that have the most impact can be identified.

Seen through the vorticity balance, the advective terms are found to roughly double the transport of both the $\mathrm{EUC}^{z}$ and the westward off-equatorial branches of the $\mathrm{SEC}^{z}$ (Fig. 7f), compared to those obtained from the linear Sverdrup circulation. Both of these changes increase the realism of the model over the Sverdrup solution (Figs. 3 and 4). The most important element of relative vorticity advection $\operatorname{curl}(\boldsymbol{\nabla} \cdot \mathbf{u} h \mathbf{u})$ is due to the deceleration of the equatorial undercurrent in the east: a large fraction of the total term is found in $-\left(u u_{x}\right)_{y}$, which can be interpreted as part of the curl of the advection terms in the zonal momentum equation or as part of the divergence of vorticity flux $(\boldsymbol{\nabla} \cdot \mathbf{u} \zeta)$, namely the zonal divergence of relative vorticity $\left[u\left(-u_{y}\right)_{x}\right]$ plus the relative vorticity times the divergence of zonal current $\left[\left(-u_{y}\right) u_{x}\right]: \operatorname{curl}(\boldsymbol{\nabla} \cdot \mathbf{u} h \mathbf{u})$ has the same sign as the wind stress curl in the east and a somewhat larger magnitude (Fig. 7b). Physically, it represents eastward advection of cyclonic relative vorticity on both sides of the equator and its convergence in the eastern Pacific. This is similar to the overshooting of western boundary currents poleward of the zero Sverdrup streamfunction line, with the $\mathrm{SEC}^{z}$ branches analogous to the associated offshore recirculation. In both cases advection of relative vorticity produces the modification to the Sverdrup circulation. Friction damps these influences but, since friction is largest in the central Pacific where the shear between the EUC and the branches of the SEC is large, 
and since vorticity effects radiate westward, the importance of friction is felt largely in the west where it reduces the effects both of the wind curl and the eastern vorticity advection, producing the observed central $\mathrm{Pa}$ cific maximum of all three currents which is not seen in the Sverdrup transport.

The FSU wind product (Stricherz et al. 1992) does not include the strip of positive curl due to the east Pacific SST front; this deficiency is similar in the mean to either the NCEP or ECMWF reanalysis winds. Hence, the Sverdrup zonal transport found from the FSU winds is very weak on the equator and has no sign of an $\operatorname{SEC}(\mathrm{N})^{z}$. However, when the OGCM is forced with the FSU winds, the solution is qualitatively similar to the ERS run, in that it does develop an $\mathrm{EUC}^{z}$ and both branches of the SEC ${ }^{z}$. These currents are about 30\% weaker than in the ERS run, and the differences are essentially the differences in the Sverdrup transport between the two wind sets. This result shows that these currents are not fundamentally due to the details of the east Pacific wind stress curl [and of course many OGCMs develop these currents even when forced with very crude winds (Philander and Pacanowski 1980)]. Even in the absence of wind stress forcing that would produce a Sverdrupian $\operatorname{SEC}(\mathrm{N})^{z}$, the effects of vorticity advection described here are sufficient to produce this current [and also the strong $\operatorname{SEC}(S)^{z}$ just south of the equator], albeit somewhat weaker than with the fully resolved curl forcing.

Our conclusion that zonal advection is the most important nonlinear effect on the vertically integrated equatorial currents is a principal difference from previous work (Philander and Pacanowski 1980), where the focus was on the role of the meridional circulation in the momentum balance. We have noted (section 4d, and see the dotted line in the top panel of Fig. 6) that in the central and western Pacific the meridional convergence of zonal momentum flux acts to intensify the $\mathrm{EUC}^{z}$ and $\mathrm{SEC}^{z}$ branches as has been argued from theory (Fofonoff and Montgomery 1955; Robinson 1966) and models (Gill 1975). However, in the eastern Pacific, zonal momentum flux diverges meridionally (primarily because the EUC occurs in the Ekman-diverging layer near the surface). More importantly, zonal divergence of zonal momentum flux (due to the acceleration and deceleration of the $\mathrm{EUC}^{z}$ ) has larger magnitude than the meridional term nearly everywhere, and is especially dominant in the east (Fig. 6). The resulting interpretation from the complete advective term in the mean zonal momentum equation is an eastward tendency within about $\pm 4^{\circ}$ latitude east of $135^{\circ} \mathrm{W}$ and a smaller westward tendency west of about $160^{\circ} \mathrm{W}$. These tendencies cannot explain the model's strong SEC branches compared to the linear (Sverdrup) circulation (cf. the middle and bottom panels of Fig. 3); in fact, they have the opposite sign.

The problem with the momentum balance approach is that there is no straightforward way to take the eastern boundary condition into account; instead, momentum balance explanations are local. That is appropriate in a time-dependent situation where the aim is to find the acceleration tendencies at each point, but does not express the dynamics in the mean, after the waves have completed the adjustment of the whole basin, including the boundaries. As Sverdrup (1947) showed, transports locally opposite to the forcing are possible once the adjustment is complete, and this is best understood from the vorticity balance with a no-normal-flow condition at the eastern boundary. The effects of the advective terms on mean zonal transport are realized not in their local value, which as we have seen would imply an eastward tendency in the region of the $\mathrm{SEC}^{z}$, but in the zonal integral of the meridional derivative of their curl [in analogy to the Sverdrup balance (5)]. These effects are eastward on the equator and westward at $\pm 2^{\circ}-4^{\circ}$ (Fig. 7f), which quantitatively explains the differences between the linear Sverdrup and total GCM transports, forced with the same winds. The existence of the SEC ${ }^{z}$ branches on the flanks of the $\mathrm{EUC}^{z}$ is due to vorticity advection that cannot be explained through the momentum balance, whose advection terms have the opposite sign. Similarly, although friction is largest in the east-central Pacific where shear between the $\mathrm{EUC}^{z}$ and the $\mathrm{SEC}^{z}$ branches is largest, the effects of friction are felt primarily in the west. The usefulness of this approach is shown in its ability to quantitatively describe the central Pacific maxima and western decay of the $\mathrm{EUC}^{z}$ and both branches of the $\mathrm{SEC}^{z}$, features that are dependent on the eastern boundary condition and are not at all obvious from the momentum balance.

Acknowledgments. Many perceptive suggestions were made by Meghan Cronin, Dudley Chelton, Peter Gent, Stuart Godfrey, Mike McPhaden, Peter Rhines, Roger Samelson, and LuAnne Thompson. Two anonymous reviewers made knowledgeable comments. Kristy McTaggart of NOAA/PMEL expertly processed much of the CTD data and combined them with the ADCP data. The ADCP data were processed by Eric Johnson, Patricia Plimpton, June Firing, and Jules Hummon. This work was supported by the NOAA Office of Oceanic and Atmospheric Research and the NOAA Office of Global Programs.

\section{APPENDIX}

\section{Eastern Boundary Condition}

The boundary condition $U_{\mathrm{EB}}(y)$ in the integral (5) for the Sverdrup zonal transport is often assumed to be zero, which is true only for a meridionally oriented eastern boundary. When $\operatorname{curl}(\tau)$ is nonzero at a tilted boundary, the Sverdrup relation (4) would imply flow normal to the boundary unless there was a corresponding zonal transport $U_{\mathrm{EB}}$ to make the total boundary flow exactly alongshore. This required value of $U$ along the coast is 
the eastern boundary condition for the zonal integral (5).

This boundary condition can be found using the Sverdrup streamfunction

$$
\psi=\frac{1}{\beta} \int_{x_{e}(y)}^{x} \operatorname{curl}(\tau) d x, \quad V=\psi_{x}, \quad U=-\psi_{y},
$$

where $x_{e}(y)$ is the longitude of the boundary at each latitude. The boundary condition for (A1) is $\psi=$ const, no matter what the boundary slope, since the no-normal flow condition precludes any contours from intersecting the coast, and we choose $\psi=0$ along the American coast. The meridional derivative of (A1) gives the complete expression for $U$ (using Liebniz's rule):

$$
\begin{aligned}
U & =-\psi_{y} \\
& =-\frac{1}{\beta}\left\{\int_{x_{e}(y)}^{x} \operatorname{curl}(\tau)_{y} d x-\left.\operatorname{curl}(\tau) \frac{d\left[x_{e}(y)\right]}{d y}\right|_{x=x_{e}(y)}\right\},
\end{aligned}
$$

where the first term on the right-hand side is the contribution to $U$ from interior wind forcing, and the second term is the value of $U$ on the boundary [ $U_{\mathrm{EB}}$ in Eq. (5)]. In that term $d\left[x_{e}(y)\right] / d y$ is the boundary slope, which is zero for a meridional coast and positive clockwise.

On a meridionally oriented coast, the boundary condition reduces to $U_{\mathrm{EB}}=0$ but, in general, the value is nonzero. For the ERS scatterometer winds studied here and the shape of the American coast, the values of $U_{\mathrm{EB}}$ are found to be small compared to the interior term except along the coast of Central America at $8^{\circ}-10^{\circ} \mathrm{N}$ where $\operatorname{curl}(\tau)$ is large and positive [associated with the Papagayo winds; see Kessler (2002)] and the coast runs northwest-southeast. In this region the values of $U_{\mathrm{EB}}$ found from (A2) were about $-10 \mathrm{~m}^{2} \mathrm{~s}^{-1}$, which is generally smaller than, but comparable to, the interior signal (Fig. 7e).

It is also noted that the above formulation is inadequate to encompass a zonally oriented coast where the slope term $d\left[x_{e}(y)\right] / d y$ becomes infinite. In that case the dynamics expressed in (2) and (3) that lead to the Sverdrup balance have no steady solution, which would require additional terms, such as friction or the radiation of coastal waves. [Another way to see this is to note that the constant- $\psi$ boundary condition on the streamfunction means that flow along a zonal coast must be exactly zonal but, if $\operatorname{curl}(\tau)$ is nonzero there, then (4) leads to a contradiction.] This is relevant to the tropical Pacific since the coastline of Mexico is approximately zonal at the Gulf of Tehuantepec (near $16^{\circ} \mathrm{N}$ ), which is also a region where the mean wind stress curl is large. Interpreting the mean wind-driven circulation in this region and to its west will require consideration of nonSverdrupian factors.
REFERENCES

Bryden, H. L., and E. C. Brady, 1989: Eddy momentum and heat fluxes and their effects on the circulation of the equatorial Pacific Ocean. J. Mar. Res., 47, 55-79.

Chelton, D. B., and Coauthors, 2001: Observations of coupling between surface wind stress and SST in the eastern tropical Pacific. J. Climate, 14, 1479-1498.

Chen, D., A. J. Busalacchi, and L. M. Rothstein, 1994a: The roles of vertical mixing, solar radiation and wind stress in a model simulation of the sea surface temperature seasonal cycle in the tropical Pacific Ocean. J. Geophys. Res., 99, 20 345-20 359.

- L. M. Rothstein, and A. J. Busalacchi, 1994b: A hybrid vertical mixing scheme and its application to tropical ocean models. $J$. Phys. Oceanogr., 24, 7725-7741.

Cronin, M. F., M. J. McPhaden, and R. H. Weisberg, 2000: Windforced reversing jets in the western equatorial Pacific. J. Phys. Oceanogr., 30, 657-676.

Donohue, K. A., E. Firing, G. D. Rowe, A. Ishida, and H. Mitsudera, 2002: Equatorial Pacific subsurface countercurrents: A modeldata comparison in stream coordinates. J. Phys. Oceanogr., 32, $1252-1264$

Fine, R. A., K. A. Maillet, K. F. Sullivan, and D. Willey, 2001: Circulation and ventilation flux of the Pacific Ocean. J. Geophys. Res., 106, 22 159-22 178.

Firing, E., 1987: Deep zonal currents in the central equatorial Pacific. J. Mar. Res., 45, 791-812.

Fofonoff, N. P., and R. B. Montgomery, 1955: The equatorial undercurrent in light of the vorticity equation. Tellus, 7, 518-521.

Gent, P. R., and M. A. Cane, 1989: A reduced gravity, primitive equation model of the upper equatorial ocean. J. Comput. Phys., 81, 444-480.

Gill, A. E., 1975: Models of equatorial currents. Proc. Symp. on Numerical Models of Ocean Circulation, National Academy of Sciences, 181-203.

Godfrey, J. S., 1989: A Sverdrup model of the depth-integrated flow for the world ocean allowing for island circulations. Geophys. Astrophys. Fluid Dyn., 45, 89-112.

Hayes, S. P., L. J. Mangum, J. Picaut, A. Sumi, and K. Takeuchi, 1991: TOGA-TAO: A moored array for real-time measurements in the tropical Pacific Ocean. Bull. Amer. Meteor. Soc., 72, 219 229.

Ji, M., R. W. Reynolds, and D. Behringer, 2000: Use of TOPEX/ Poseidon sea level data for ocean analyses and ENSO prediction: Some early results. J. Climate, 13, 216-231.

Johnson, E. S., and D. S. Luther, 1994: Mean zonal momentum balance in the upper and central equatorial Pacific Ocean. J. Geophys. Res., 99 (C4), 7689-7705.

Johnson, G. C., B. S. Sloyan, W. S. Kessler, and K. E. McTaggart, 2002: Direct measurements of upper ocean currents and water properties across the tropical Pacific Ocean during the 1990s. Progress in Oceanography, Vol. 52, Pergamon, 31-61.

Kessler, W. S., 1999: Interannual variability of the high-salinity tongue south of the equator at $165^{\circ} \mathrm{E}$. J. Phys. Oceanogr., 29, 2038-2049.

_ 2002: Mean three-dimensional circulation in the northeast tropical Pacific. J. Phys. Oceanogr., 32, 2457-2471.

—_, and B. A. Taft, 1987: Dynamic heights and zonal geostrophic transports in the central tropical Pacific during 1979-84. J. Phys. Oceanogr., 17, 97-122.

_ L. M. Rothstein, and D. Chen, 1998: The annual cycle of SST in the eastern tropical Pacific, as diagnosed in an ocean GCM. J. Climate, 11, 777-799.

Landsteiner, M. C., M. J. McPhaden, and J. Picaut, 1990: On the sensitivity of Sverdrup transport estimates to the specification of wind stress forcing in the tropical Pacific. J. Geophys. Res., 95, 1681-1691.

Levitus, S., 1982: Climatological Atlas of the World Ocean. NOAA Prof. Paper 13, 173 pp. and 17 microfiche. 
McCreary, J. P., 1981: A linear stratified model of the equatorial undercurrent. Philos. Trans. Roy. Soc. London, 298A, 603-635.

— , P. Lu, and Z.-J. Yu, 2002: Dynamics of the Pacific subsurface countercurrents. J. Phys. Oceanogr., 32, 2379-2404.

McPhaden, M. J., and B. A. Taft, 1988: Dynamics of seasonal and interannual variability in the eastern equatorial Pacific. J. Phys. Oceanogr., 18, 1713-1732.

— , and Coauthors, 1998: The Tropical Ocean-Global Atmosphere observing system: A decade of progress. J. Geophys. Res., 103, 14 169-14 240.

Meyers, G., 1980: Do Sverdrup transports account for the Pacific North Equatorial Countercurrent? J. Geophys. Res., 85, 10731075 .

Murtugudde, R., and A. J. Busalacchi, 1998: Salinity effects in a tropical ocean model. J. Geophys. Res., 103, 3283-3300.

Philander, S. G. H., and R. C. Pacanowski, 1980: The generation of equatorial currents. J. Geophys. Res., 85, 1123-1136.

—, and P. Delecluse, 1983: Coastal currents in low latitudes (with application to the Somali and El Niño currents). Deep-Sea Res. 30, 887-902.

Qiu, B., and R. Lukas, 1996: Seasonal and interannual variability of the North Equatorial Current, the Mindanao Current and the Kuroshio along the Pacific western boundary. J. Geophys. Res., 101, $12315-12330$

Robinson, A. R., 1966: An investigation of the wind as the cause of the equatorial undercurrent. J. Mar. Res., 24, 179-204.
Rossow, W. B., and R. A. Schiffler, 1991: ISCCP cloud data products. Bull. Amer. Meteor. Soc., 72, 2-20.

Rowe, G. D., E. Firing, and G. C. Johnson, 2000: Pacific equatorial subsurface countercurrent velocity, transport, and potential vorticity. J. Phys. Oceanogr., 30, 1172-1187.

Seager, R. S. E. Zebiak, and M. A. Cane, 1988: A model of the tropical Pacific sea surface temperature climatology. J. Geophys. Res., 93, 1265-1280.

Stoffelen, A., and D. L. T. Anderson, 1997: Scatterometer data interpretation: Measurement space and inversion. J. Atmos. Oce anic. Technol., 14, 1298-1314.

Stricherz, J., J. J. O'Brien, and D. M. Legler, 1992: Atlas of Florida State University Tropical Pacific Winds for TOGA 1966-1985. The Florida State University, 275 pp.

Sverdrup, H. U., 1947: Wind-driven currents in a baroclinic ocean, with application to the equatorial currents of the eastern Pacific. Proc. Natl. Acad. Sci. USA, 33, 318-326.

Wajsowicz, R. C., 1999: Variations in gyre closure at the water mass crossroads of the western equatorial Pacific Ocean. J. Phys Oceanogr., 29, 3002-3024.

Wallace, J. M., T. P. Mitchell, and C. Deser, 1989: The influence of SST on surface wind in the eastern equatorial Pacific: Seasonal and interannual variability. J. Climate, 2, 1492-1499.

Yu, Z., and M. J. McPhaden, 1999: Dynamical analysis of seasonal and interannual variability in the equatorial Pacific. J. Phys. Oceanogr., 29, 2350-2369. 